\title{
Variation in Lipid Content of Strains of Histoplasma capsulatum Exhibiting Different Virulence Properties for Mice ${ }^{1}$
}

\author{
H. S. NIELSEN, JR. ${ }^{2}$ \\ Department of Microbiology and Immunology, Duke University Medical Center, \\ Durham, North Carolina
}

Received for publication 16 September 1965

\begin{abstract}
Nielsen, H. S., JR. (Duke University Medical Center, Durham, N.C.). Variation in lipid content of strains of Histoplasma capsulatum exhibiting different virulence properties for mice. J. Bacteriol. 91:273-277. 1966.-Lipid content and virulence were studied in six isolates of Histoplasma capsulatum in an attempt to determine whether or not the two factors could be correlated in this fungus. Virulence was evaluated by injecting dba line 1 male mice intracerebrally with $2.8 \times 10^{4}$ infective yeast-phase units and recording organ involvement and spontaneous deaths occurring in a 20-day period. Yeast cells were extracted with mixtures of ethyl alcohol-diethyl ether $(3: 1, \mathrm{v} / \mathrm{v})$, and the total extractable lipid, as determined by solubility in petroleum ether, was separated into acetone-soluble and phospholipid fractions by acetone precipitation. Neutral lipids were measured directly by weighing, whereas total phospholipids were calculated after the colorimetric determination of phosphorus. The mixed phosphatides of two isolates, differing in virulence, were separated into five fractions by use of a column of silicic acid and Hyflo Super-Cel. In the six isolates studied, neither total extractable lipid, acetone-soluble lipid, nor phospholipid showed a quantitative correlation with virulence. Phosphatidylserine, cephalin, phosphoinositides, and sphingolipids were present in essentially the same amounts in the two strains investigated; however, a lecithin fraction was absent in the less virulent form. These data suggest that the quantity of phosphatidylcholine demonstrated for a given isolate of $\boldsymbol{H}$. capsulatum may provide some insight as to its virulence, although such a relationship is lacking for total lipid, the acetone-soluble fraction, and the combined phospholipids of yeast-phase growth.
\end{abstract}

In 1950, Bloch (4) published a paper on the isolation of a substance from Mycobacterium tuberculosis termed "cord factor," which was highly toxic for certain strains of mice and appeared to be associated only with virulent bacilli. Noll and Bloch (11) reported the chemical structure of this material to be trehalose-6, $6^{\prime}$-dimycolate, and, subsequently, Kato et al. (8) showed a decrease in the activity of certain dehydrogenase enzymes in liver homogenates after the intraperitoneal injection of the substance in mice. These findings supported earlier observations

${ }^{1}$ Part of a dissertation submitted to the graduate school of The Ohio State University in partial fulfillment of requirements for the Ph.D. degree.

${ }^{2}$ Present address: Department of Microbiology, Duke University, Durham, N.C. that the activity of succinic dehydrogenase decreases with an increase in the severity of experimental tuberculosis.

Although lipoidal compounds analogous to the "cord factor" have not been found in the human pathogenic fungi, the fact that many similarities exist between the pathology of tuberculosis and some systemic mycoses (16) suggests that the factor(s) responsible for disease might also be similar. In a chemical study of assorted fungi, Peck and Hauser (15) observed a qualitative difference in the phospholipids of saprophytic species and those which are pathogenic for man. Peck (12) later suggested that the lipid component of pathogenic forms might be associated with mycotic infection through interfering with hostenzyme systems and by influencing the absorp- 
tion properties of the parasite. Baker (3) found that the phosphatides of Blastomyces dermatitidis stimulated the infiltration of monocytes in mice; however, he concluded that these compounds were probably not responsible for the pathology of blastomycosis, since they failed to induce polymorphonuclear neutrophiles and to cause necrosis. More recently, Di Salvo and Denton (5) reported findings which suggest that the amount of lipid present in the blastomyces yeast cell might be an important factor in the virulence of this organism. In their study of four isolates, total extractable lipids increased from $6.8 \%$ in an avirulent form to $12.3 \%$ in a highly virulent strain.

To investigate the possibility that a similar relationship might also exist in another fungus causing systemic infection in man, quantitative data on the total lipids, acetone-soluble lipids, and phospholipids of six isolates of Histoplasma capsulatum were obtained and compared with the virulence of these isolates for mice. In addition, the mixed phospholipids of two isolates were studied in detail to determine whether or not specific compounds might be correlated with virulence.

\section{Materials AND Methods}

The six isolates of $\boldsymbol{H}$. capsulatum studied were obtained from The Ohio State University Hospital, and the Mycology Unit, National Institute of Allergy and Infectious Diseases. Isolates H-100, Strauser, G-17, 6651 , and G-8 were recovered from human cases of histoplasmosis, and isolate G-12 was isolated from a dog.

Yeast cells were propagated in culture tubes $(25 \times$ $150 \mathrm{~mm}$ ) on a synthetic medium consisting of $0.1 \%$ cysteine hydrochloride, $1.0 \%$ casein hydrolysate, $1.0 \%$ dextrose, $0.25 \% \quad \mathrm{NaH}_{2} \mathrm{PO}_{4}, 0.25 \% \mathrm{KCl}, \mathbf{0 . 0 2 \%}$ $\mathrm{MgSO}_{4}, 2.0 \%$ agar (Difco), $1 \mathrm{ml}$ of trace elements (composition per liter of distilled water: $\mathrm{H}_{3} \mathrm{BO}_{3}$, $0.114 \mathrm{~g} ;\left(\mathrm{NH}_{4}\right)_{6} \mathrm{Mo}_{2} \mathrm{O}_{24} \cdot 4 \mathrm{H}_{2} \mathrm{O}, 0.484 \mathrm{~g} ; \mathrm{CuSO}_{4} \cdot 5 \mathrm{H}_{2} \mathrm{O}$, $0.780 \mathrm{~g} ; \mathrm{MnCl}_{2} \cdot 14 \mathrm{H}_{2} \mathrm{O}, 0.114 \mathrm{~g}$; and $\mathrm{ZnSO}_{4} \cdot \mathrm{TH}_{2} \mathrm{O}$, $16.720 \mathrm{~g}$ ), and $1 \mathrm{ml}$ of vitamins (composition per liter of distilled water containing $20 \%$ ethyl alcohol at pH 4.5: thiamine hydrochloride, $2.0 \mathrm{mg}$; pyridoxine hydrochloride, $1.0 \mathrm{mg}$; pyradoxamine dihydrochloride, $0.5 \mathrm{mg}$; pyridoxal hydrochloride, $0.5 \mathrm{mg}$; calcium panthothenate, $2.0 \mathrm{mg}$; riboflavine, $2.0 \mathrm{mg}$; nicotinic acid, $1.0 \mathrm{mg}$; $p$-aminobenzoic acid, $0.1 \mathrm{mg}$; biotin, $0.05 \mathrm{mg}$; and inositol, $1.0 \mathrm{mg}$ ). In all experiments, cultures were incubated for $72 \mathrm{hr}$ at $37 \mathrm{C}$, and growth from the same harvest of cells was used for both animal injection and lipid extraction.

Animal inoculum was prepared according to the procedure previously described by Rowley and Huber (17), with slight modification. Briefly, yeast cells were collected in cold $0.86 \%$ saline containing $1 \%$ cysteine; the cells were pooled and then washed by centrifugation three times in fresh saline-cysteine solution. Washed cells were differentially centrifuged at $\mathbf{3 5 0}$ $\mathrm{rev} / \mathrm{min}$ to sediment large cell aggregates, and the supernatant liquid was carefully removed by aspiration. Each suspension was standardized by the platecount method to contain $5.6 \times 10^{5}$ infective units per $\mathrm{ml}$, and $0.05 \mathrm{ml}\left(2.8 \times 10^{4}\right.$ infective units) was injected intracerebrally into young adult dba line 1 male mice weighing between 12 and $20 \mathrm{~g}$. (An infective unit is defined as any condition which would give rise to a single colony on Sabouraud Dextrose Agar, i.e., a single cell, a budding cell, or an aggregate of cells.) Virulence in each isolate was evaulated on the basis of spontaneous deaths and organ involvement in two groups of 10 animals in a 20-day period. Portions of brain, liver, spleen, and lung from injected animals were removed at autopsy, macerated by repeated chopping with scissors, and cultured on Sabouraud Dextrose Agar containing chloramphenicol $(0.05 \mathrm{mg} / \mathrm{ml})$ and cycloheximide $(0.5 \mathrm{mg} / \mathrm{ml})$.

Prior to extraction, yeast cells were killed with $0.5 \%$ formalin, washed three times in distilled water by centrifugation, and suspended after the final washing in a known volume of distilled water. The dry weight of the total sample was calculated from the average weight of five dried samples.

Total lipids were extracted and fractionated according to the method of Hanahan, Dittmer, and Warashina (6), modified to include a mild hydrolysis with $1 \% 1.0 \mathrm{~N} \mathrm{HCl}$ after extraction with $95 \%$ ethyl alcohol. Phospholipid phosphorus was determined colorimetrically by the method of King (9) and recorded as micrograms of phospholipid phosphorus or percentage of phospholipid, according to the method of Hawk, Oser, and Summerson (7). Acetone-soluble lipids were measured directly by weighing, after the evaporation of this fraction to dryness.

The mixed phospholipids of isolates G-12 and H-100 were separated into component fractions by chromatography with a column of silicic acid and Hyflo Super-Cel, as described by Hanahan et al. (6). Fractions were eluted with a series of chloroformmethanol mixtures $(4: 1,3: 2,1: 4, \mathrm{v} / \mathrm{v})$ under positive pressure with nitrogen gas. Phospholipid phosphorus was determined on every fifth tube of eluate.

\section{RESUlts}

In a series of preliminary experiments conducted for the purpose of measuring the dose response to isolate $\mathrm{H}-100$ for dba line 1 male mice, the intracerebral injection of $2.8 \times 10^{4}$ infective units was found to kill 50 and $100 \%$ of inoculated animals in 10 and 20 days, respectively. On the basis of these observations, this dosage was adopted for use in the present investigation.

The results of two experiments in which the death-producing properties and recovery from infected organs were evaluated for the isolates in question are recorded in Table 1. From these studies, it is clear that isolates $\mathbf{H - 1 0 0 , ~ G - 8 , ~ a n d ~}$ Strauser were most virulent. The death rate of animals exposed to these strains ranged between 80 and $100 \%$, and the fungus was recovered from 
TABLE 1. Mortality and percentage recovery of six isolates of Histoplasma capsulatum from dba line 1 male mice

\begin{tabular}{|c|c|c|c|c|c|}
\hline \multirow{2}{*}{ Isolate } & \multirow{2}{*}{$\begin{array}{c}\text { Animal deaths } \\
\text { in } 20 \text { days } \\
\text { (dead/total) }\end{array}$} & \multicolumn{4}{|c|}{ Percentage recovery } \\
\hline & & Brain & Lungs & Liver & Spleen \\
\hline \multirow[t]{2}{*}{ H-100. } & $10 / 10$ & 80 & 80 & 70 & 70 \\
\hline & $10 / 10$ & 100 & 80 & 80 & 80 \\
\hline \multirow[t]{2}{*}{ G-8 } & $10 / 10$ & 80 & 80 & 80 & 80 \\
\hline & $10 / 10$ & 100 & 80 & 80 & 80 \\
\hline \multirow[t]{2}{*}{ Strauser. } & $8 / 10$ & 80 & 80 & 80 & 80 \\
\hline & $9 / 10$ & 100 & 80 & 80 & 50 \\
\hline \multirow[t]{2}{*}{ G-12. } & $6 / 10$ & 30 & $\mathbf{0}$ & 30 & 0 \\
\hline & $4 / 10$ & 30 & 20 & 0 & 0 \\
\hline \multirow[t]{2}{*}{6651} & $0 / 10^{*}$ & $\mathbf{0}$ & 0 & 0 & 0 \\
\hline & $6 / 10$ & 70 & 30 & 0 & 0 \\
\hline \multirow[t]{2}{*}{ G-17. } & $4 / 10$ & 50 & 0 & 0 & 0 \\
\hline & $5 / 10$ & 70 & 30 & 0 & 20 \\
\hline
\end{tabular}

* This is not considered to represent the virulence of this isolate, since accompanying plate counts were negative.

50 to $100 \%$ of cultured organs, including brain, lung, liver, and spleen. In contrast, isolates G-12, G-17, and 6651 killed only 40 to $60 \%$ of inoculated mice, and the number of organs supporting fungus growth after 3 weeks of incubation differed significantly from that of the previous group. Cultures of brain were positive in 30 to $70 \%$ of injected animals, whereas macerates of lung, liver, and spleen tissue varied from 0 to $30 \%$ positive.

Animals dying spontaneously after inoculation were free of gross symptoms of histoplasmosis, and the histological sections of brain stained with hematoxylin and eosin and by the periodic acid-Schiff reaction showed large areas of monocytic infiltration, but few intracellular yeast. Evidence of meningitis from microscopic preparations was not a constant finding in surviving mice, which were autopsied at the end of 8 weeks. However, in the majority of animals which were subsequently proven to harbor the fungus by culture, lesions were observed on the viscera and omentum, and, in some cases, hyperplasia of the liver and spleen was present.

Generally speaking, the quantity of lipid demonstrated for a single isolate appeared characteristic and showed a reasonable degree of conformation between replicate studies. The acetone-soluble component of yeast cells ranged from 4.9 to $9.2 \%$ by dry weight, whereas phospholipids varied from 0.26 to $1.25 \%$ (Table 2).

The order in which the six strains occurred, in reference to quantity of acetone-soluble fraction, paralleled that for total lipid. Based on the results of two studies, isolate H-100 contained
TABLE 2. Lipid content of yeast cells of six isolates of Histoplasma capsulatum

\begin{tabular}{|c|c|c|c|c|}
\hline Isolate & $\begin{array}{l}\text { Total } \\
\text { lipid }\end{array}$ & $\begin{array}{l}\text { Acetone- } \\
\text { soluble lipid }\end{array}$ & $\begin{array}{c}\text { Phospho- } \\
\text { lipid }\end{array}$ & $\begin{array}{l}\text { P1-AL } \\
\text { ratio }\end{array}$ \\
\hline & $\%$ & $\%$ & $\%$ & \\
\hline \multirow[t]{2}{*}{ H-100. } & 10.25 & 9.00 & 1.25 & 14.0 \\
\hline & 10.30 & 9.20 & 1.10 & 12.0 \\
\hline \multirow[t]{2}{*}{ G-8. } & 6.31 & 5.40 & 0.91 & 16.8 \\
\hline & 6.00 & 5.20 & 0.80 & 15.4 \\
\hline \multirow[t]{2}{*}{ Strauser. . } & 9.56 & 8.60 & 0.96 & 11.1 \\
\hline & 9.40 & 8.50 & 0.90 & 10.6 \\
\hline \multirow[t]{2}{*}{ G-12. } & 5.41 & 4.90 & 0.51 & 10.6 \\
\hline & 5.80 & 5.20 & 0.60 & 11.5 \\
\hline \multirow[t]{2}{*}{6651 . } & 7.26 & 7.00 & 0.26 & 3.7 \\
\hline & 7.40 & 7.10 & 0.30 & 4.2 \\
\hline \multirow[t]{2}{*}{ G-17 } & 6.50 & 5.60 & 0.90 & 16.0 \\
\hline & 6.70 & 5.80 & 0.90 & 15.5 \\
\hline
\end{tabular}

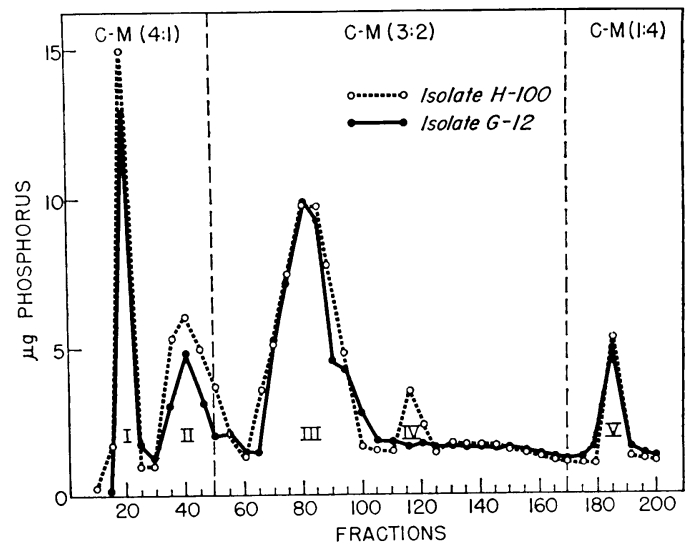

FIG. 1. Graphical representation of the phospholipid fractions of isolates $\mathrm{H}-100$ and $\mathrm{G}-12$ in micrograms of phosphorus: (I) phosphatidylserine, (II) phosphatidylethanolamine, (III) phosphoinositides, (IV) phosphatidylcholine, and $(V)$ sphingolipids.

the largest amount of acetone-soluble material, with an average of $9.1 \%$. Strauser and 6651 were intermediate, with percentages of 8.55 and 7.05 , respectively, and isolates G-17, G-8, and G-12 contained the smallest amounts, with respective values of $5.7,5.3$, and $5.05 \%$.

Calculated phospholipids varied between 0.26 and $1.25 \%$ by dry weight in the six strains and accounted for approximately 10 to $15 \%$ of the total petroleum ether-soluble compounds. Isolate H-100 contained the largest amount of this fraction, with an average of $1.17 \%$ from duplicate experiments. Strauser, G-17, and G-8 were characterized by averages of $0.93,0.90$, and $0.86 \%$, respectively, and G-12 contained $0.56 \%$. Phospholipid of isolate 6651 constituted approximately $4 \%$ of the total lipid fraction and $0.28 \%$ of the 
TABLE 3. Phospholipid fractions of two isolates of Histoplasma capsulatum

\begin{tabular}{|c|c|c|c|c|c|c|c|c|c|c|c|c|c|}
\hline Isolate & \multicolumn{2}{|c|}{$\begin{array}{c}\text { Phosphatidyl- } \\
\text { serine }\end{array}$} & \multicolumn{2}{|c|}{ Cephalin } & \multicolumn{2}{|c|}{ Phosphoinositides } & \multicolumn{2}{|c|}{ Lecithin } & \multicolumn{2}{|c|}{ Sphingolipids } & \multirow{2}{*}{$\begin{array}{c}\begin{array}{c}\text { Amt frac- } \\
\text { tionated }\end{array} \\
\mu g \\
416.00 \\
520.00\end{array}$} & \multirow{2}{*}{$\begin{array}{c}\begin{array}{c}\text { Amt re- } \\
\text { covered }\end{array} \\
\mu g \\
351.50 \\
446.00\end{array}$} & \multirow{2}{*}{$\begin{array}{c}\begin{array}{c}\text { Per cent } \\
\text { recov- } \\
\text { ery }\end{array} \\
\\
84.43 \\
85.70\end{array}$} \\
\hline $\begin{array}{l}\text { G-12. } \\
\mathrm{H}-100 .\end{array}$ & $\begin{array}{l}\mu g \\
40 \\
45\end{array}$ & $\begin{array}{c}\% \\
11.13 \\
10.08\end{array}$ & $\begin{array}{c}\mu g \\
77.5 \\
110.0\end{array}$ & $\begin{array}{c}\% \\
22.07 \\
24.29\end{array}$ & $\begin{array}{c}\mu g \\
194.0 \\
220.0\end{array}$ & $\begin{array}{c}\% \\
55.67 \\
49.32\end{array}$ & $\begin{array}{r}\mu g \\
0 \\
35\end{array}$ & $\frac{\%}{7.84}$ & $\begin{array}{c}\mu g \\
40.0 \\
36.0\end{array}$ & $\begin{array}{c}\% \\
11.13 \\
8.07\end{array}$ & & & \\
\hline
\end{tabular}

dry weight of the organism. The relationship between this component and the neutral lipid fraction is given in Table 2 (P1-ASL ratio).

Of a total of $416 \mu \mathrm{g}$ of phospholipid phosphorus from G-12 which was added to the silic acid column for separation, $351.5 \mu \mathrm{g}$, or $84.43 \%$, was recovered in the combined eluate. Corresponding figures for H-100 were $520.0 \mu \mathrm{g}$ of total initial phospholipid phosphorus and $446.0 \mu \mathrm{g}$ of recovered phosphorus, representing a recovery of 85.7\%. Both values are near the expected percentage of recovery for this method (6). In both strains, the phosphoinositide fraction accounted for approximately $50 \%$ of the combined phospholipid phosphorus. Cephalin was present in amounts ranging between 20 and $25 \%$, and phosphatidylserine and the spingolipids each comprised about $10 \%$ of the total phospholipid mixture. Lecithin occurred as $7.84 \%$ of isolate H-100; however, this fraction was not demonstrated for G-12. These data are recorded in Fig. 1 and in Table 3.

\section{Discussion}

Peck and Hauser (13) found yeast cells of $B$. dermatitidis to contain 8.5 to $9.5 \%$ lipid by dry weight. Phospholipids made up 0.7 to $3.0 \%$ of the organism's dry weight and constituted as much as $34.3 \%$ of the total extractable lipid. In a subsequent study, these investigators (14) reported that Candida albicans contained $5.3 \%$ lipid by dry weight with the acetone-insoluble component accounting for approximately $3 \%$ of this value. In both fungi, the combined lipid fraction represented a mixture of lecithin, cephalin, glycerides, free fatty acids, and sterols.

These observations are in close agreement with the findings of Di Salvo and Denton (5) for the yeast phase of $B$. dermatitidis. In four isolates of the fungus, total extractable lipids ranged from 6.8 to $12.3 \%$, and phospholipid varied between 1.4 and $7.1 \%$ (averaging 3 to $4 \%$ in the majority of experiments).

Previous reports on the composition of $\boldsymbol{H}$. capsulatum indicate that a substantial amount of the fungus occurs as lipid. Al-Doory (1) found that free lipids of yeast-phase growth accounted for nearly $20 \%$ of the fungus, and that phospholipid phosphorus comprised approximately $0.2 \%$. In a more recent paper, Al-Doory and Larsh (2) reported that the total extractable lipids of yeast cells ranged between 18 and $37.8 \%$, and that the phospholipid component varied from 6.8 to $12.0 \%$. These values are significantly higher for both lipid fractions than those reported in this study, although it is difficult to compare data, since different strains, media, and extraction and fractionation procedures were employed in the two investigations.

From the data presented in Tables 1 and 2, it can be seen that the relationship between total extractable lipid, the combined acetone-soluble and phospholipid fractions, and virulence is not a direct one. Isolates H-100, G-8, and Strauser produced higher mortality rates in inoculated mice than did G-12, 6651, and G-17, although the total extractable lipid and the acetone-soluble fraction of G-8 were less than those of 6651 and G-17. Furthermore, isolate G-17 killed only $50 \%$ of inoculated mice, yet contained essentially the same amount of phospholipid as G-8 and Strauser. Some of the data (those related to the total lipid component) are not consistent with the observations of Di Salvo and Denton (5) for $B$. dermatitidis; however, they do suggest that a direct relationship between total extractable lipid and virulence, as reported by these workers, is probably an individual rather than common property of human pathogenic fungi. That such a correlation could exist is understandable, since Lindegren (10) showed that lipid accumulation markedly affects the biochemistry of the yeast cell.

As illustrated in Fig. 1, the chromatograms of isolates H-100 and G-12 were very similar. Phosphatidylserine, cephalin, phosphoinositides, and the sphingolipids were present in both strains in essentially the same proportions; however, lecithin was not found in the mixed phosphatides of the moderately virulent strain G-12. What significance this has in terms of a lecithin-virulence relationship remains to be established, although it should be emphasized that even the amount of phosphatidylcholine recorded for $\mathrm{H}-100$ is exceptionally low when compared with that reported for other organisms. In the nonpathogenic 
yeast, Saccharomyces cerevisiae, lecithin accounts for as much of the total phospholipid phosphorus as cephalin and nearly as much as inositol phosphatide (6). Both G-13 and H-100 contained large amounts of phosphoinositides and phosphatidylethanolamine; when combined, these fractions accounted for approximately $76 \%$ of the total recovered phospholipid phosphorus. Peck (12) reported the presence of lecithin and cephalin in the lipids of $B$. dermatitidis and $C$. albicans and referred to a carbohydrate-containing phospholipid which he did not name, but stated that it was found mostly in connection with pathogenic as opposed to nonpathogenic fungi. It is possible that the substance could be a phosphoinositide or a sphingolipid, as both fractions were represented in the yeast cells of H. capsulatum.

\section{ACKNOWLEDGMENTS}

The author expresses his appreciation to J. A. Schmitt, Jr., W. D. Gray, and R. M. Johnson for their help in this study.

\section{LITERature Cited}

1. Al-Doory, Y. 1960. Free lipids and phospholipid phosphorus of Histoplasma capsulatum and other pathogenic fungi. J. Bacteriol. 80: 565-566.

2. Al-DOORY, Y., AND H. W. LARSH. 1962. Quantitative studies of total lipids of pathogenic fungi. Appl. Microbiol. 10:492-495.

3. BAKER, R. D. 1942. Experimental blastomycosis in mice. Am. J. Pathol. 18:463-478.

4. ВLOCH, H. 1950. Studies on the virulence of tubercle bacilli. Isolation and biological properties of a constituent of virulent organisms. $J$. Exptl. Med. 91:197-217.

5. Di Salvo, A. F., AND J. F. Denton. 1963. Lipid content of four strains of Blastomyces dermatitidis of different mouse virulence. J. Bacteriol. 85:927-931.

6. Hanahan, D. J., J. C. Dittmer, and E. WaraSHINA. 1957. A column chromatographic sepa- ration of classes of phospholipids. J. Biol. Chem. 228:685-700.

7. HaWk, P. B., B. L. OSER, AND W. H. SUMmerSON. 1947. Practical physiological chemistry, 12th ed. Blakiston Co., Philadelphia.

8. Kato, M., K. Miki, K. Matsunaga, And Y. YAMAMURA. 1958. Biological and biochemical activities of "cord factor." Am. Rev. Tuberc. Pulmonary Diseases 77:482-491.

9. KING, E. J. 1932. The colorimetric determination of phosphorus. Biochem. J. 26:292-297.

10. Lindegren, C. C. 1945 . The introduction of dormancy in vegetative yeast cells by fat and carbohydrate storage and the conditions for reactivation. Arch. Biochem. 8:119-134.

11. Noll, H., AND H. Bloch. 1956. The chemical structure of the cord factor of Mycobacterium tuberculosis. Biochim. Biophys. Acta 20:299309.

12. PeCK, R. L. 1947. The lipids of fungi with special reference to pathogenic fungi, p. 167-188. In W. J. Nickerson [ed.], Biology of pathogenic fungi. Chronica Botanica Co., Waltham, Mass.

13. PeCK, R. L., AND C. R. Hauser. 1938. Chemical studies of certain pathogenic fungi. I. The lipids of Blastomyces dermatitidis. J. Am. Chem. Soc. 60:2599-2603.

14. PeCK, R. L., AND C. R. HAuser. 1939. Chemical studies of certain pathogenic fungi. II. The lipids of Monilia albicans. J. Am. Chem. Soc. 61:281-284.

15. PeCK, R. L., AND C. R. Hauser. 1940. Chemical studies on certain pathogenic fungi. III. Further studies on the lipids of Blastomyces dermatitidis and Monilia albicans. J. Biol. Chem. 193:403-412.

16. Pinkerton, H. 1960. Differential diagnosis, p. 424-448. In H. C. Sweany [ed.], Histoplasmosis. Charles C Thomas, Publisher, Springfield, Ill.

17. Rowley, D. A., AND M. Huber. 1955. Pathogenesis of experimental histoplasmosis in mice. I. Measurement of infective dosages of the yeast phase of Histoplasma capsulatum. J. Infect. Diseases 96:174-183. 